\title{
Management of Hydrocephalus in Brain Tumors to Fann Teaching Hospital in Dakar
}

\author{
Alioune Badara Thiam, Maguette Mbaye, Rel Gerald Boukaka Kala, Mbaye Thioub, \\ Cheick Ndiaye SY, Mohamet Faye, Sarah Mutomb Ntshindj, Ndaraw Ndoye, Momar Codé BA, \\ Seydou Boubakar Badiane
}

Department of Neurosurgery, Fann Teaching Hospital, University Cheikh Anta Diop, Dakar, Senegal

Email address:

maguette.mbaye8@gmail.com (M. Mbaye)

\section{To cite this article:}

Alioune Badara Thiam, Maguette Mbaye, Rel Gerald Boukaka Kala, Mbaye Thioub, Cheick Ndiaye SY, Mohamet Faye, Sarah Mutomb Ntshindj, Ndaraw Ndoye, Momar Codé BA, Seydou Boubakar Badiane. Management of Hydrocephalus in Brain Tumors to Fann Teaching Hospital in Dakar. International Journal of Neurosurgery. Vol. 4, No. 1, 2020, pp. 1-6. doi: 10.11648/j.ijn.20200401.11

Received: October 9, 2019; Accepted: November 28, 2019; Published: January 21, 2020

\begin{abstract}
Introduction: Tumoral hydrocephalus (TH) is an increasingly common pathology in our service. It is a diagnostic and especially therapeutic emergency. Its treatment is mainly surgical and the prognosis closely depends on the type of tumor. The objective of our study was to determine the efficiency of the various bypass procedures used for the treatment of hydrocephalus in patients with brain tumors. Patients and Methods: We conducted a retrospective study of 146 patients with tumoral hydrocephalus, collected from 1 January 2014 to 31 December 2018 (5 years) in the Neurosurgery Department of Fann Teaching Hospital. Results: The frequency of tumoral hydrocephalus cases in our series was rated at $25 \%$ of all hydrocephalus operated during this period with 29.2 cases per year. The sex ratio was 1.39 with a mean age of 35 years (range from 1 month to 77 years). Children under 15 accounted for $53.42 \%$. Cerebral computed tomography (CT) was performed in $93.75 \%$ of patients and magnetic resonance imaging (MRI) in $20.83 \%$. Tumors of the posterior fossa (PFT) accounted for $60.3 \%$ followed by ventricular tumors $15.5 \%$ and sellar $7.5 \%$. Surgically, endoscopic third ventriculostomy (ETV), ventriculoperitoneal shunt (VPS), and external ventricular derivation (EVD) were performed respectively in $58.24 \%, 30.13 \%$ and $10.27 \%$ of cases. The surgical average time was 3 days with extremes of $24 \mathrm{~h}$ and 150 days. Two patients benefited from a ventriculo -atrial shunt (VAS) complementary to the persistence of hydrocephalus. The main complications were ascites of great abundance in 4 patients and infections in 10 patients (6.84\%). In our series, $30.82 \%$ (45 patients) received additional etiological treatment. The average time between the two interventions was 14 days. We noted 17 cases of death including 7 cases attributed to hydrocephalus. Conclusion: The endoscopic third ventriculostomy is currently the gold standard as an alternative to other methods in the management of tumoral hydrocephalus, but remains a palliative treatment. Etiological treatment is the core therapeutic approach for this hydrocephalus.
\end{abstract}

Keywords: Hydrocephalus, Brain Tumor, Endoscopic Third Ventriculostomy

\section{Introduction}

Tumoral hydrocephalus is a neurosurgical condition that can occur at any age. It is usually secondary to a disorder of the hydrodynamics of the cerebrospinal fluid (CSF) by hyperproduction or most often by obstruction during its flow. The diagnosis has been easily set up since brain CT scan has been promoted throughout Senegal. In its acute phase, $\mathrm{TH}$ remains a surgical emergency. The urgent bypass of this TH is one of the options among the broad therapeutic approaches. We distinguish endoscopic third ventriculostomy and different ventricular shunt (ventriculoperitoneal, ventriculo- atrial, ventriculo-pleural and external derivation). The availability of these technical means in such urgent condition is life-saving. However, the prognosis of tumor hydrocephalus is closely related to the histological character of the tumor and sometimes to its topography. The objective of our study was to point out the efficiency of the various shunt procedures used in the treatment of hydrocephalus in patients with brain tumors.

\section{Patients and Methods}

This is a retrospective study conducted on 156 patients 
treated for hydrocephalus over a 5-year-period range from 1 January 2014 to 31 December 2018 at the Neurosurgery Department Neurosurgery of FANN Teaching Hospital. All patients diagnosed with tumoral hydrocephalus who underwent a shunt procedure with or without brain tumor removal were included in our study. We excluded in our series, all patients derived for tumoral hydrocephalus whose histology was in favor of an infectious process (brain tuberculoma) and all those with an unusable record. The data were collected from the clinical observation forms and reported on a survey form. The parameters taken in the medical records were epidemiological (age, sex, consultation time), clinical, paraclinical, therapeutic: (time of the surgery, type of intervention, duration of intervention); and evolution (duration of hospitalization, complications). The diagnosis was made on the basis of the clinical course and brain imaging (CT and MRI). Urgent hydrocephalus derivation was indicated by acute elevated intracranial pressure features (intense headaches, resistant to usual analgesics, incoercible vomiting, nerve VI involvement, signs of cerebral involvement, visual disturbances). Presence of ependymal resorption with an Evans index greater than $50 \%$ on the cerebral imaging. The surgical technique of CSF derivation was discussed according to the topography of the tumor and the initial clinical symptoms. The patients were shunted either by endoscopic third ventriculostomy (ETV), ventriculoperitoneal shunt (VPS), external ventricular derivation (EVD) and ventriculo-atrial shunt (VAS). The surgery was performed by different operators. All our patients benefited from immediate prophylactic antibiotic treatment. The patients underwent general anesthesia with orotracheal intubation. EVD, the most urgent gesture, has been performed under local anesthesia in acute elevated ICP in patients with impaired consciousness (Glasgow <10). The VPS was made by the same type of drain "Chhabra ${ }^{\circledR}$ ". The EVD was kept for 7 days. It was the most transient derivation technique.

The endoscopic material was a Karl Storz ${ }^{\circledR}$ type endoscopic column with rigid $30^{\circ}$ optic. For VPS and VAS, we used the non-adjustable Chhabra ${ }^{\circledR}$ valve with middle pressure. The postoperative assessment was made and included clinical, ophthalmological fundus, and neuroradiological data (Brain CT scan +++ ). We noted a good outcome according to clinical data improvement after the surgical approach. Regular monitoring was carried out over a period of 3 months. To conduct this work, ethical permission was allowed from Ethical Committee of Fann Teaching Hospital at Dakar.

\section{Results}

The frequency of tumoral hydrocephalus cases in our series was $25 \%$ of all hydrocephalus with 29.2 cases per year. There was a male predominance $(85 / 61)$ with a sex ratio of 1.39 (Figure 1). The average age was 35 years with extremes of 1 month and 77 years. Children under 15 years accounted for $53.42 \%$. Lesions were multiple in $3.42 \%$ of cases. Cerebral computed tomography (CT) was performed in $93.75 \%$ of patients and magnetic resonance imaging (MRI) in $20.83 \%$ of cases. Posterior fossa tumors (PFT) accounted for $60.3 \%$ followed by $15.5 \%$ ventricular tumors and $7.5 \%$ sellae tumors (Table 1). Endoscopic third ventriculostomy was performed in 85 patients $(58.24 \%)$, ventriculoperitoneal shunt in 44 patients $(30.13 \%)$ and external ventricular derivation (EVD) in 15 patients with of conscious impairment associated with raised ICP $(10,27 \%)$. The average time for surgery was 3 days with extremes of $24 \mathrm{~h}$ to 150 days. This delay varied according to the type of intervention and clinical symptoms. For the EVD, the delay was $24 \mathrm{~h}$, that of the ETV was 2 days and that of the VPS was 7 days. Two patients benefited from a VAS. Complementary to the persistence of hydrocephalus after the first VPS. The latter was performed in one patient for persistent hydrocephalus after excision of a craniopharyngioma and another in an ependymoma of 4th ventricle. Twelve patients have undergone a reintervention for persistent hydrocephalus before the month following the first surgery. The main complications were ascites of great abundance in 4 patients and infections in $6.84 \%$. In our series, 45 patients received additional etiological treatment after controlling hydrocephalus. The average time between the two interventions was 14 days with extremes of 2 and 405 days. We had 17 deaths whose 7 were attributed to hydrocephalus.

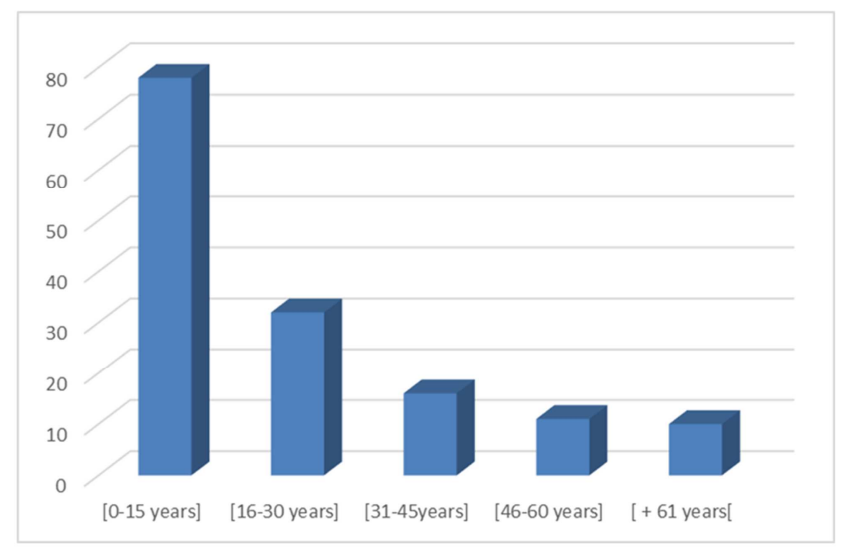

Figure 1. Distribution of patients by age.

Table 1. Distribution of topography and surgery.

\begin{tabular}{llll}
\hline Location & Topograpgy & Number & Pourcent (\%) \\
\hline Sub-tentorial & Vermis & 41 & 28,08 \\
& Cerebellum & 18 & 14,28 \\
& Brain stem & 9 & 6,16 \\
& Tentorial & 3 & 2,05 \\
& $4^{\text {th }}$ ventricle & 4 & 2,73 \\
& Clivus & 1 & 0,67 \\
Supratentorial & CPA & 12 & 8,21 \\
& Pineal & 7 & 4,80 \\
& Sellar & 16 & 7,5 \\
& Ventricular & 22 & 15,06 \\
& Septum pellicidum & 01 & 0,67 \\
& Thalamus & 04 & 2,73 \\
& Diencephalic & 01 & 0,68 \\
Supratentorial and & Hemispheric & 04 & 2,73 \\
supratentorial & & 03 & 2,05 \\
\hline
\end{tabular}


Table 2. Type of surgery.

\begin{tabular}{lll}
\hline Surgical techniques & Number & Percentage (\%) \\
\hline ETV & 85 & 58,24 \\
VPS & 44 & 30,13 \\
EVD & 15 & 10,27 \\
VAS & 2 & 1,36 \\
\hline
\end{tabular}

\section{Discussion}

Tumoral hydrocephalus is a pathology found at any age. They represent $25 \%$ of all hydrocephalus. However, it affects more than $50 \%$ of children. This is explained by the predominance of the localization of posterior fossa lesions in this age group. The male prevalence found in our study is similar to the literature $[17,18,22]$. The long diagnostic delay is common in developing countries. However, the time of diagnosis is such long because of the slow growth of benign tumors [17]. The signs of elevated ICP remain the most frequent circumstance of discovery, mainly indicating the diagnosis delay. Patients consult only when serious neurological disorders occur. Cerebral computed tomography (CT) was performed in $93.75 \%$ of patients and magnetic resonance imaging (MRI) in $20.83 \%$ of cases. Triventricular hydrocephalus predominated in our study with $60.3 \%$ versus $12.6 \%$ of biventricular hydrocephalus. This is related to the predominance of CPF lesions. The CT-scan remains the first-line examination in our regions [19]. It is available and and roughly performed for emergency use. It is sometimes enough to make the diagnosis. Eye fundus makes it possible to evaluate the visual prognosis and to appreciate the impact of ventricular dilatation. It was performed in $1 / 3$ of our patients, especially those with sellae lesions. This is explained by the fact that this assessment is systematic before any sellae and suprasellar lesion. Our hospital structure does not have ophthalmologists and this examination should not delay surgical management. In our series, the treatment of hydrocephalus was performed before the tumor removal in $30.87 \%$. The average time between the two interventions was 14 days (range from 2 days to 405 days).

\subsection{Hydrocephalus and Posterior Fossa Tumors}

\subsubsection{Place of ETV}

ETV is now recognized as the treatment of choice in obstructive hydrocephalus. In our series, it was performed in the first 48 hours after hospitalization. It was carried out in $65 \%$ of cases. It takes more and more an important place. Besides its availability for emergency use, this technique was chosen because of its timely and simple realization. It was performed on the basis of a triventricular hydrocephalus. It has become a reliable alternative for the management of this pathology. Its advantages such a quality of life improvement and a low morbidity rate make it a technique of choice, especially in developing countries [15, 17, 23]. Hydrocephalus, frequently associated with posterior fossa tumors (PFT) is not always resolved after tumor excision; this has led some authors to recommend an ETV prior to tumor surgery [18].

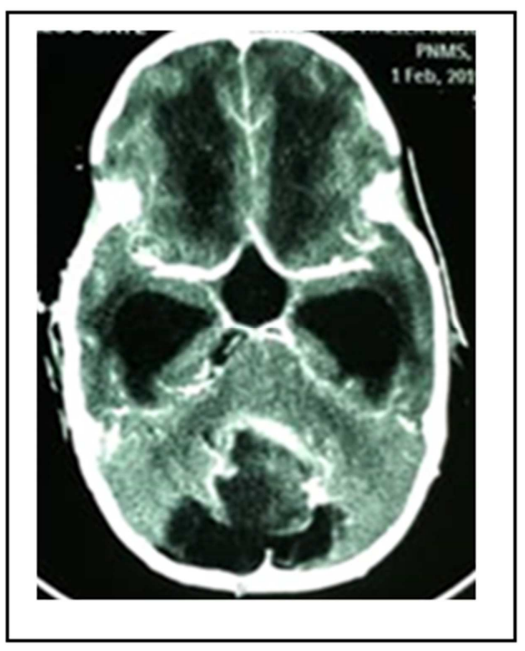

Figure 2. Brain CT-scan: hydrocephalus in medulloblastoma in a 3-year-old child.

\subsubsection{Place of the VPS}

In our context, it has been realized on the basis of hydrocephalus that occurs after a tumor that evolves in the brainstem. Brainstem tumors (BST) represent a heavy condition and involve a multidisciplinary management.

If ETV remains the main treatment, BST cause anatomical changes with the closure of pre-pontic cistern preventing this technique. Sufficient space between the basilar artery and the clivus below the 3 rd ventricle floor is a prerequisite for the success of an ETV [12]. Thus, a ventriculoperitoneal or atrial shunt seems to be a valid alternative when patients have unfavorable anatomy for an ECV. In our context, the VPS remains the definitive treatment for a curative surgery because of a lack of appropriate facilities. Also, for Fournier and al [11] the realization of the VP shunts as a $1^{\text {st }}$ line approach or in case of failure of ETV in the management of metastatic PCF tumor. Ekouele-Mbaki [9] carried out a VPS in $26.47 \%$ of the cases before the tumoral hydrocephalus any topography confused.

\subsection{Hydrocephalus and CPA Tumors}

In our series, hydrocephalus was found in CPA tumors in $100 \%$ of cases (12 patients). All these patients had had an emergency VP shunt; until they are fit for excision surgery. In a series of 284 CPA tumors, Pirouzmand and al [20] found 39 cases of hydrocephalus. Only 4 required emergency derivation. This high frequency of shunt in our series is explained by the presence of acute signs of raised ICP during admission and by the size of the lesions. On the other hand, several authors agree on the primary treatment of the tumor in the absence of these signs of the acute elevated ICP $[13,20]$.

\subsection{Hydrocephalus and Pineal Tumors}

Today, regarding their care, the new recommendations order to treat hydrocephalus at first, and then determine the histological pattern of the tumor in order to choose the appropriate therapeutic approach that will achieve maximum efficiency on the tumor with a minimal functional and vital outcome. In patients with poor prognostic tumors, such as 
pinealoblastoma, choriocarcinoma, hydrocephalus management may be the only therapeutic option [4]. In Kennedy series, ETV was achieved in $85.7 \%$ of cases [4]. In our series, the ETV was realized at $100 \%$. It was urgently performed and guided a simultaneous biopsy that allows a CSF specimen for cytological purpose and helps research tumor markers. ETV was converted to EVD in 2 patients with anatomical variations. However, while most authors advocate ETV [1], others [21] advocate a VPS because of the occurrence the obliteration of the $3 \mathrm{rd}$ ventricle in $15 \%$ of cases. In our context, the possible dissemination along the CSF in case of malignant tumor [14] makes this technique less practicable.

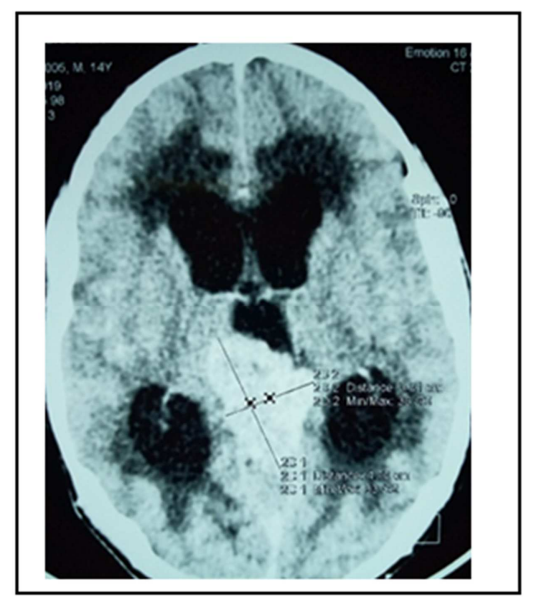

Figure 3. Brain CT-scan showing a pineal tumor with triventricular hydrocephalus benefiting from ETV.

\subsection{Hydrocephalus with Sellae and Suprasellae Tumors}

In craniopharyngiomas, hydrocephalus is found in 40 to $60 \%$ of cases $[5,16]$. In our series, the VP shunt was the treatment of choice because of the acute raise of ICP threatening the visual prognosis during admission. The VPS was performed in 4 patients: 4 children with craniopharyngiomas and 1 pituitary adenoma before the signs related on raised ICP especially with visual threat and 1 VP shunt after surgery of excision in our context. This technique allowed a good preparation of the excision in 4 patients. It was the only treatment for hydrocephalus in large and calcified craniopharyngioma. In craniopharyngiomas, the derivation of hydrocephalus is recommended in order to prepare a good surgery. It can also be the definitive treatment for very large lesions with the very risky surgery. However, some authors recommend the establishment of a reservoir of Omaya under endoscopic control in cystic craniopharyngiomas (risk of functional complications of VPS) [24]. In our study, 4 patients who had a sellae and suprasellae tumor presented ascites after VP shunt placement. Ascites is a rare mechanical complication of VP shunt. It is mainly related to disorders of CSF reabsorption following a difference of pressure in the peritoneum. According to these complications, revision or removal of the drain is necessary. Two patients benefited from an externalization of the abdominal drain in a bag for several weeks. One underwent ascites puncture followed by drain removal and then DVA. One patient was discharged against medical consent without taking charge of his ascites.

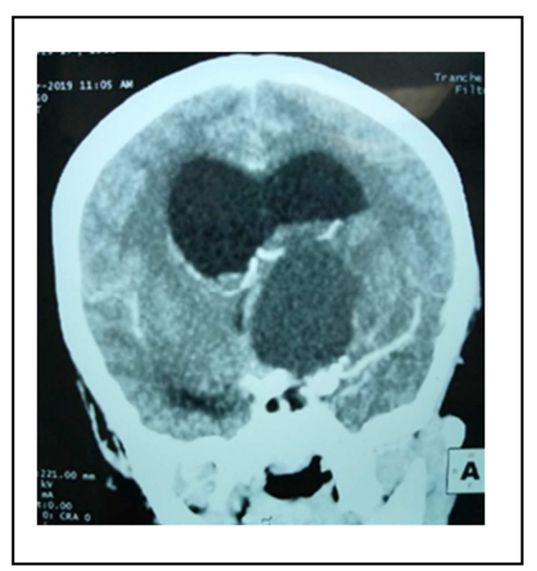

Figure 4. Brain CT scan showed hydrocephalus with cystic craniopharyngioma.

\subsection{Hydrocephalus and Intra-ventricular Tumors}

\subsubsection{Tumor of $V 3$}

During these last years, the indications of VCE have been extended to deep tumors, particularly ventricular tumors [3]. It revolutionized the therapeutic strategy of tumors evolving through the third ventricle (V3) because besides allowing the treatment of hydrocephalus, it helps perform a simultaneous biopsy of the tumor mass [8]. In our series, out of 11 patients treated for V3 tumors, 5 had VCS. However, this technique was effective only in 2 patients. It was converted to EVD in 3 patients for uncontrolled hemorrhage in 2 patients and anatomical changes in 1 patient. Depending on the histological pattern of the lesion, particularly the density of the cystic lesions, some authors advocate internal derivation as the only alternative [7]. The internal derivation was performed in our series, for persistent hydrocephalus after tumor excision. Cyst-ventriculostomy using a drain positioned in stereotactic conditions has been described by some authors [10].

\subsubsection{Hydrocephalus with Lateral Ventricle (LV) Tumor}

In the Baroncini series on LV tumors [3], 2/3 of the patients had CSF dynamic disorders and $6.5 \%$ had a VP shunt (sometimes in the second intention after the failure of weaning EVD). In our series, all our patients had hydrocephalus and $4 / 5$ of the patients needed an emergency VP shunts. Only one patient benefited from an external bypass. This high VP shunt rate is explained by both as a transient choice for better preparation before excision and by the fear of infectious complications related to EVD in our context. But this last technique is an urgent technique that is solvating when the patient presents an acute raised ICP with consciousness disorders. Several authors reported the effectiveness of EVD in the management of hydrocephalus of LV tumors [25]. However, the best treatment for hydrocephalus in LV tumors is excision of the tumor itself [11]. Thus, when hydrocephalus 
is well tolerated, it can be respected. Fournier [11] rightly considers that hydrocephalus shunt is not quite necessary with an internal derivation as soon as the diagnosis is made. The drain exposes itself to a risk of mechanical complications related to tumor micro bleeding and hyper-albuminorachia. No patient has had a VCS in our series.

\subsubsection{Hydrocephalus and Thalamic Tumor}

In the Baroncini series on thalamic tumors [2], significant hydrocephalus was present in four patients. Two of these required emergency endoscopic third ventriculostomy and the other had a ventriculoperitoneal shunt. In our series, four pediatric patients presented acute ICH. They underwent a VPS (100\%). This is explained by the fact that in our series, this localization is characterized by malignant lesions with rapid development. The risk of closing the stoma would be higher. While some authors reported a poor outcome after VPS [12], this technique remains the only alternative to relieve the patient and extend the survival of the patient.

The prognosis was favorable in $65 \%$ of patients. Apart from the complications due to tumor progression, the derivation may also lead to complications. Twelve patients died for persistent hydrocephalus in the month following surgery. These patients had no clinical improvement after the treatment of hydrocephalus and they have had a cerebral CT scan confirming the persistence of hydrocephalus. The persistence of hydrocephalus has been related to the failure of CSF derivation techniques. One patient presented disconnection of the drain that was found 3 days after the derivation in absence of improvement of the clinical course and confirmed with the cerebral CT-Scan. She received a drain revision. 2 patients were dependent of EVD. The latter had hydrocephalus on a pineal tumor. The onset of infectious complications occurred in 3 weeks. All patients with infectious complications received antibiotic treatment with different drugs that mostly included ceftriaxone, metronidazole, and gentamycin. One patient died of a septicemia. The combination of several complications would increase the risk of death.

\section{Conclusion}

Tumoral hydrocephalus remains a therapeutic emergency. The classical techniques of derivation remain the therapeutic options in our context. ETV is currently the core therapy approach as an alternative to other methods. The rate of favorable outcome depends mainly on the early diagnosis and treatment. The failures are mostly related to the initial clinical condition of patients, the histological pattern and the tumor topography. However, this treatment remains a palliative treatment and etiological treatment is the main therapeutic management for this hydrocephalus.

\section{Conflict of Interest Statement}

The authors states that there is no conflict of interest.

\section{References}

[1] Bauer BL, Hellwig D. Minimally invasive endoscopic neurosurgery--a survey. Acta Neurochir Suppl. 1994; 61: 1-12.

[2] Baroncini, M., Vinchon, M., Minéo, JF. et al. Childs Nerv Syst (2007) 23: 753. https://doi.org/10.1007/s00381-007-0299-4.

[3] Baroncini M, Peltier J, Le gars D, Lejeune JP: Tumeurs du ventricule latéral. Analyse d'une série de 284 cas. Neurochir 2011; 57 (4-6): 170-179.

[4] Benjamin C. Kennedy, Jeffrey N. Bruce. Surgical Approaches to the Pineal Region Neurosurgery Clinics of North America, July 2011; 22 (3): 367-80.

[5] Choux M, Lena G. Bases of surgical management of craniopharyngioma in children proceedings. Acta Neurochir Suppl (Wien). 1979; 28 (2): 348.

[6] Christian Matula. Chapter 37 - Tumors of the Pineal Region. Principles of Neurological Surgery (Third Edition) 2012: 565-84.

[7] Creissard. P, Godleuski J, Tadie M, Freger P Faut-il aborder les kystes colloides du 3e ventricule. Neurochirurgie, 1981, 27: 225-228.

[8] Deopujari CE, Karmarkar VS, Shaikh ST Endoscopic Third Ventriculostomy: Success and Failure; J Korean Neurosurg Soc. 2017 May; 60 (3): 306-314; DOI: 10.3340/jkns.2017.0202.013.

[9] Ekouel-Mbaki H. B, M. Elombila, G. F Etiobanda, G. A Panzou, P. M. Ossou-Guiet Prise en charge neuro-chirurgicale des tumeurs cranio-encéphaliques au Centre Hospitalier Universitaire de Brazzaville (Congo); Médecine d'Afrique Noire, Juin 2018, Vol 65, No6: 291-298.

[10] Carl El Khoury, Pierre Brugières, Philippe Decq, Ruxandra Cosson-Stanescu, Catherine Combes, Frédéric Ricolfi and André Gaston. Colloid Cysts of the Third Ventricle: Are MR Imaging Patterns Predictive of Difficulty with Percutaneous Treatment? American Journal of Neuroradiology, March 2000, 21 (3) 489-492.

[11] Fournier D, Pasco-papan A, Menei P, Mercier P, Guy G. Tumeurs intraventriculaire EMC-Neurologie 1997 [Article17250-A-10].

[12] Goel A (2000); Preoperative shunts in thalamic tumors. Neurol India 48: 347-350.

[13] Gonzalez LF, Gregory P. Lekovic and col; Surgical Approaches to the cerebellopontine Angle. In: Nicholas C. Bambakidis, Md, Cliff A. Megerian, Robert F. Spetzler. Surgery of the Cerebellopontine Angle. BC Decker. 2009. p53-72.

[14] Guyotat J, Vasiljevic A, Frappaz D, Durand A, Fèvre Montange $\mathrm{M}$, Jouvet A. Tumeurs de la région pinéale. EMC - Neurologie 2011; 17-380-D-10.

[15] Jan Gliemroth, Eva Käsbeck, Uwe Kehler Ventriculocisternostomy versus ventriculoperitoneal shunt in the treatment of hydrocephalus: A retrospective, long-term observational study; Clinical Neurology and Neurosurgery, Volume 122, July 2014, Pages 92-96.

[16] Lena G, Paz Paredes A, Scavarda D, Giusiano B. Craniopharyngioma in children: Marseille experience. Childs Nerv Syst. 2005 Aug; 21 (8-9): 778-84. 
[17] M Mbaye, M Thioub, AB Thiam, CN Sy, R G Boukaka, J. Kissao, MC BA, SB Badiane; Treatment of tumor hydrocephalia by endoscopic ventriculo-cisternostomy; Journal Africain de Chirurgie 2017; 4 (3): 131-136.

[18] Morelli D., Lubansu A., Van Bogaert P., Frickx C., David P., Brotchi J., Pirotte B. Hydrocéphalie persistante après exérèse chirurgicale précoce des tumeurs de la fosse postérieure: analyse critique rétrospective d'une série consécutive de 160 enfants. CONGRÈS SNCLF; Vol. 50, n 5, 2004, P 57.

[19] Ousseini Diallo, Ouattara Boubakar, Zanga Moussa, Tiemtore-Kambou Bénilde, N'de/Ouedraogo Nina, Dao Ben Aziz, Napon A Madina, Bamouni Y Abel, Lougue/Sorgho Claudine, Cisse Rabiou; Etiological diagnosis of macrocranies explored by CT in Burkina Faso (70 cases) Journal Africain d'Imagerie Médicale 2016, Volume 8 (4): 159-163.

[20] Pirouzmand F, Tator CH, Rutka J. Management of hydrocephalus associated with vestibular schwannoma and other Cerebellopontine Angle Tumors. Neurosurgery. 2001 Jun $1 ; 48$ (6): 1246-1254.

[21] Quenum K, Y Sogoba, M Hemama, A Hossinand, Laghmari M, Gana R, Maaqili R, Bellakhdar $F$ Tumeurs de la région pinéale: expérience des dix dernières années. À propos de 22 cas. Neurochirurgie 2008; 54 (5): 684-5.
[22] Alexandre Roux, Céline Botella, Megan Still, Marc Zanello, Frédéric Dhermain, Philippe Metellus, Johan Pallud. Posterior Fossa Metastasis-Associated Obstructive Hydrocephalus in Adult Patients: Literature Review and Practical Considerations from the Neuro-Oncology Club of the French Society of Neurosurgery. World Neurosurg. 2018 Sep; 117: 271-279. doi: 10.1016/j.wneu.2018.06.084. Epub 2018 Jun [PubMed].

[23] S. Salem-Memou, A. Badara Thiam, E. Kpelao, M. Mbaye M. C. Ba S. B. Badiane; Treatment of child hydrocephalus by endoscopic third ventriculostomy in Senegal; Volume 60, Issue 5, October 2014, Pages 254-257.

[24] Stephanie Puget, Kevin Beccaria, Claire Alapetite, Dulanjalee Kariyawasam, Michel Polak, Delphine Zenaty, Raphael Calmon, Christian Sainte-Rose. Les craniopharyngiomes de l'enfant: stratégie de prise en charge: Journée National du DES (JNDES), Médecine Clinique Endocrinologie et Diabète (MCED)/ MCED No86 Janvier 2017: P 12-15.

[25] Zuccaro Graciela, Sosa Fidel, Cuccia Vicente, Lubienecky Fabiana, Monges Jorge; Lateral ventricle tumors in children: a series of 54 cases Child's Nerv Syst (1990) 15: 774-785. 